\title{
The Effects of A Cognitive Training Program for Older Adults: A Brief Preliminary Report
}

\author{
Nathan Jensen, Caroline Kinskey, and Jeffrey Buchanan \\ Minnesota State University - Mankato
}

\section{ABSTRACT}

As one ages, some degree of cognitive decline is expected. Despite this, declines in cognitive abilities and the possibility of dementia is a common concern among older adults. In response to these concerns, a variety of cognitive training programs have been developed that aim to improve or maintain cognitive *Correspondence to Author: Jeffrey Buchanan, Ph.D. func-tioning. Prior literature has shown mixed or limited findings on cognitive changes after implementation of cognitive training. This study evaluated the effectiveness of a cognitive training program designed for older adults with no to minimal cognitive decline. The current study included 17 participants who engaged in two one-hour cognitive training sessions each week for 12 weeks. Each session required participants to complete activities that targeted the following cognitive domains: attention, visual and verbal memory, visual spatial skills, processing speed and executive functioning, and language. These cognitive domains, along with depression and memory self-efficacy, were assessed prior to and immediately after completion of the program. Small to large effect sizes on the majority of cognitive outcome mea-sures were observed following participation in the program. Small reductions in depressive symptoms were also found. These findings Department of Psychology, 103 Armstrong Hall, Mankato, MN, USA 56001.

provide preliminary support for the use of a com-prehensive How to cite this article:

Nathan Jensen, Caroline Kinskey, and Jeffrey Buchanan. The Effects of A Cognitive Training Program for Older Adults: A Brief Preliminary Report. International Journal of Aging Research, 2021, $4: 86$ cognitive training program for cognitively-intact older adults.

Keywords: aging, older adults, cognitive interventions, cognitive assessment, cognitive training 
As adults age, many begin to notice declines in cognitive abilities and report things such as, "I'm not as sharp as I used to be." In fact, as people age, they tend to experience "age-associated cognitive decline" (Deary et al., 2009). Skills that typically slow or decline with age include: processing speed and reaction time, divided and sustained attention, various memory abilities (e.g., working, episodic memory), verbal fluency, confrontation naming, visual construction, cognitive flexibility, and response inhibition (Harada, Natelson-Love, \& Triebel, 2013; Salthouse, 2012). The severity of deterioration and the degree of negative impact on functioning varies greatly across individuals (Deary et al., 2009; Salthouse, 2012). For instance, negative effects may include periodic embarrassment, frustration, or emotional distress. More significantly, subjective complaints of cognitive decline are associated with greater depressive symptoms and may lead to concerns about the possibility of developing dementia (Minett, Da Silva, Ortiz, \& Bertolucci, 2007).

In response to concerns about cognitive decline and dementia, cognitive training programs have been created with the goal of improving or maintaining cognitive abilities. "Cognitive training" refers to interventions that use guided practice on a set of standardized tasks that target specific cognitive functions (Bahar-Fuchs, Clare, \& Woods, 2013). Cognitive training typically takes place in small groups and is comprised of a standardized, structured program of activities (Belleville, 2008). The goal of cognitive training is to improve cognitive functioning, sustain functioning, or slow cognitive decline. The assumption underlying cognitive training is that the brain remains plastic as people age, so practicing cognitive activities will improve or maintain functioning (Hertzog, Kramer, Wilson, \& Lindenberger, 2008).

Many "brain game" products on the market claim to improve cognitive abilities, but many exaggerate the positive effects of their programs and can mislead consumers (Simons et al., 2016). Conversely, recent reviews of the empirical literature conclude that cognitive training may result in some circumscribed benefits. Gross and associates (2012) examined studies targeting memory functioning in community-dwelling, cognitively-intact older adults. The authors found that memory training interventions resulted in improvements larger than retest effects in control groups and that training participants in multiple memory strategies produced larger gains. Simons and colleagues (2016) also reviewed the "brain training" literature and found evidence for improvements on trained tasks, but little evidence of benefits on related cognitive tasks or everyday cognitive functioning.

\section{Purpose of Current Study}

The current study collected preliminary data regarding the effectiveness of a cognitive training program that was implemented in an independent living facility for retired nuns. Based on prior research, improvements on measures of executive functioning, processing speed, and verbal and visual memory were hypothesized to occur (Ball et al., 2002; Gross et al., 2012). Analyses concerning attention, visuospatial skills, and language were exploratory in nature given that few studies have examined the impact of cognitive training on these abilities. In addition, it was hypothesized that participants would report improvements in memory self-efficacy because of expectations about the benefits of cognitive training. Finally, participating in cognitive training represents an attempt to mitigate worries about declines in cognitive functioning, so it was hypothesized that participants would report fewer depressive symptoms after the program.

\section{Method}

\section{Participants}

Participants were recruited from a facility serving retired nuns located in a small Midwestern metropolitan area in the United States. To be included in the study, participants were required to achieve a score of 78 or above on the Modified Mini-Mental Status Examination (3MS; 
Teng \& Chui, 1987), which is the "intact/mild" range. 3MS scores ranged from 81-97 $(M=$ $92.2, S D=4.63$ ). Exclusion criteria included a 3MS score below 78 or the presence of significant visual, hearing, or motor impairments that could prevent successful participation in the program. The presence or absence of a neurocognitive disorder, however, was not an exclusion criterion because staff reported that some individuals were a good fit for the program and met all inclusion criteria despite having a diagnosis of neurocognitive disorder. Likewise, staff observed other individuals who were experiencing cognitive decline, but did not have a diagnosis of neurocognitive disorder. Therefore, diagnostic status appeared to be an imperfect indicator of the severity of cognitive impairment and appropriateness for the program.
A convenience sample of 18 individuals participated, although one participant dropped out prior to completing the program. All other participants completed at least $75 \%$ of the classes (range $=79-100 \%, M=94.4 \%$ ). All participants were Caucasian women that had at least a bachelor's degree. Ages ranged from 7193 years old $(M=82.82, S D=7.30)$. Five individuals carried a diagnosis of a condition that affects cognitive functioning (e.g., dementia), with two of these individuals taking medication for dementia. In addition, seven participants carried a diagnosis of major depressive disorder, with five taking antidepressant medication and one taking an anxiolytic. The dosages of all medications remained unchanged throughout the study.

\section{Table 1 Outcome Measures}

\begin{tabular}{|c|c|}
\hline Cognitive Domain & Instrument \\
\hline Global Cognitive Ability & Modified Mini-Mental State Examination (3MS; Teng \& Chui, 1987) \\
\hline & Forward \& Backward Digit Span (Wechsler, 2008) \\
\hline Attention & Brief Test of Attention (Schretlen, 1997) \\
\hline Visual Memory & Brief Visuospatial Memory Test - Revised (Benedict, 1996) \\
\hline Verbal Memory & Hopkins Verbal Learning Test (Brandt \& Benedict, 2001) \\
\hline Visual Spatial Skills & Visual Puzzles (Wechsler, 2008) \\
\hline $\begin{array}{l}\text { Processing Speed \& Executive } \\
\text { Functioning }\end{array}$ & Trail Making Test Part A \& B (Reitan \& Davidson, 1974) \\
\hline Language & $\begin{array}{l}\text { Controlled Oral Word Association Test (Benton \& Hamsher, 1989) } \\
\text { Boston Naming (Kaplan, Goodglass, \& Weintraub, 1983) }\end{array}$ \\
\hline Depression & $\begin{array}{l}\text { Patient Health Questionnaire-9 Observer Version (Kroenke, Spitzer, \& } \\
\text { Williams, 2002) }\end{array}$ \\
\hline Memory Selt-efficacy & $\begin{array}{l}\text { Cognitive Failures Questionnaire (Broadbent, Cooper, FitzGerald \& Parkes, } \\
\text { 1982) }\end{array}$ \\
\hline
\end{tabular}

\section{Materials}

The cognitive training program used in this study was created by the New England Cognitive Center (NECC) and was called Mind Sharpener. The program is designed for adults with no or very mild cognitive decline and who report subjective cognitive decline that does not interfere with completing daily activities.

Prior to the start of the study, a master trainer from the NECC trained staff to deliver the Mind Sharpener program. A manual that included detailed instructions about how to deliver the

IJOAR: https://escipub.com/international-journal-of-aging-research/ 
program was also provided. The program included 24, one-hour classes delivered twice a week over a twelve-week period. Two separate classes were delivered in a group format, with both groups initially including nine participants. Each class included a sequence of paper-and-pencil activities related to six cognitive domains: processing speed, attention, visuospatial skills, short-term memory, language, and problem solving. Activities within each domain took approximately 5-12 minutes and gradually increased in difficulty as the program progressed.

Table 2 Results of Paired-Sample t-test for Cognitive and Non-Cognitive Measures

\begin{tabular}{|c|c|c|c|c|c|c|c|}
\hline \multirow[t]{2}{*}{ Measure } & \multicolumn{2}{|l|}{ Pre } & \multirow{2}{*}{$\frac{\text { Post }}{M}$} & \multirow[b]{2}{*}{ SD } & \multirow[b]{2}{*}{$t$} & \multirow[b]{2}{*}{$d f$} & \multirow[b]{2}{*}{$\begin{array}{l}\text { Sig. }(2- \\
\text { tailed) }\end{array}$} \\
\hline & $\overline{\mathrm{M}}$ & SD & & & & & \\
\hline Global Cognitive Ability (3MS) & 92.24 & 4.63 & 94.00 & 5.65 & 1.31 & 16 & .209 \\
\hline $\begin{array}{l}\text { Simple Attention (Forward Digit } \\
\text { Span) }\end{array}$ & 8.71 & 1.69 & 8.88 & 2.15 & .447 & 16 & .661 \\
\hline $\begin{array}{l}\text { Working Memory (Backward Digit } \\
\text { Span) }\end{array}$ & 8.18 & 2.19 & 8.71 & 1.96 & 1.21 & 16 & .245 \\
\hline Divided Attention (BTA) & 5.76 & 2.51 & 6.94 & 2.41 & 2.14 & 16 & $.048^{*}$ \\
\hline $\begin{array}{l}\text { Processing Speed/Executive } \\
\text { Functioning (Trails A) }\end{array}$ & 50.35 & 20.85 & 43.94 & 16.07 & -1.60 & 16 & .130 \\
\hline $\begin{array}{l}\text { Processing Speed/Executive } \\
\text { Functioning (Trails B) }\end{array}$ & 126.94 & 46.46 & 114.88 & 47.71 & -1.59 & 16 & .131 \\
\hline Immediate Verbal Recall (HVLT) & 19.41 & 4.23 & 23.18 & 4.68 & 4.25 & 16 & $.001^{* * *}$ \\
\hline Delayed Verbal Recall (HVLT) & 6.29 & 2.69 & 8.12 & 2.29 & 2.67 & 16 & $0.017^{*}$ \\
\hline Verbal Recognition (HVLT) & 9.47 & 1.38 & 10.29 & 1.49 & 3.57 & 16 & $0.003^{* *}$ \\
\hline Immediate Visual Recall (BVMT-R) & 14.47 & 7.72 & 16.06 & 7.55 & 1.54 & 16 & .142 \\
\hline Delayed Visual Recall (BVMT-R) & 5.82 & 3.43 & 6.59 & 3.55 & 1.42 & 16 & .175 \\
\hline Visual Recognition (BVMT-R) & 5.00 & 1.37 & 5.29 & 1.31 & 1.16 & 16 & .264 \\
\hline $\begin{array}{l}\text { Language/Executive Functioning } \\
\text { (COWAT) }\end{array}$ & 27.12 & 7.73 & 26.35 & 11.10 & -0.39 & 16 & .703 \\
\hline Language (Boston Naming) & 24.88 & 2.74 & 25.00 & 2.98 & 0.20 & 16 & .847 \\
\hline Visual-Spatial (Visual Puzzles) & 10.71 & 2.52 & 11.41 & 2.69 & 0.97 & 16 & .346 \\
\hline Depression (PHQ-9) & 5.47 & 4.30 & 4.59 & 4.47 & -1.07 & 16 & .302 \\
\hline Perception of Memory (CFQ) & 34.94 & 13.10 & 34.00 & 12.36 & -0.36 & 16 & .720 \\
\hline
\end{tabular}

${ }^{*} \mathrm{p}<.05 ;{ }^{* *} \mathrm{p}<.01 ;{ }^{* * *} \mathrm{p}<.001$

\section{Experimental Design and Procedure}

Because this was a pilot study designed to assess the potential benefits of the program, a pre-post quasi-experimental design was employed. After signing a consent form (approved by the Institutional Review Board), the researchers administered a battery of neuropsychological tests to assess the six cognitive domains targeted by the program one 
week prior to starting the program and within one week following the completion of the program. In addition, participants completed measures of memory self-efficacy and mood (Table 1 lists all outcome measures).

\section{Results}

A paired-samples t-test was conducted to determine the effects of the program on cognitive functioning, depressive mood, and memory self-efficacy. There was a statistically significant difference in the scores for divided attention, $\mathrm{t}(16)=2.14, p=.048$; immediate verbal recall, $t(16)=4.25, p=.001$; delayed verbal recall, $\mathrm{t}(16)=2.67, \mathrm{p}=.017$; and verbal recognition, $\mathrm{t}(16)=3.57, p=.003$ (see Table 2).

Table 3 Effect Size Results for Cognitive and Non-Cognitive Measures

\begin{tabular}{|c|c|c|c|c|}
\hline \multirow{3}{*}{$\begin{array}{l}\text { Measure } \\
\text { Global Cognitive Ability (3MS) }\end{array}$} & \multicolumn{2}{|c|}{ 95\% Confidence Interval } & \multirow[b]{2}{*}{ Cohen's d } & \multirow[b]{2}{*}{ Interpretation } \\
\hline & Lower & Upper & & \\
\hline & -0.322 & 1.033 & 0.36 & Small Effect \\
\hline Simple Attention (Forward Digit Span) & -0.576 & 0.769 & 0.12 & No Effect \\
\hline $\begin{array}{l}\text { Working Memory (Backward Digit } \\
\text { Span) }\end{array}$ & -0.396 & 0.956 & 0.28 & Small Effect \\
\hline Divided Attention (BTA) & -0.174 & 1.192 & 0.51 & Moderate Effect \\
\hline $\begin{array}{l}\text { Processing Speed/Executive } \\
\text { Functioning (Trails A) }\end{array}$ & -1.033 & 0.323 & -0.36 & Small Effect \\
\hline $\begin{array}{l}\text { Processing Speed/Executive } \\
\text { Functioning (Trails B) }\end{array}$ & -1.07 & 0.287 & -0.39 & Small Effect \\
\hline Immediate Verbal Recall (HVLT) & 0.375 & 1.817 & 1.10 & Large Effect \\
\hline Delayed Verbal Recall (HVLT) & -0.081 & 1.294 & 0.61 & Moderate Effect \\
\hline Verbal Recognition (HVLT) & 0.199 & 1.611 & 0.93 & Large Effect \\
\hline Immediate Visual Recall (BVMT-R) & -0.307 & 1.049 & 0.37 & Small Effect \\
\hline Delayed Visual Recall (BVMT-R) & -0.325 & 1.03 & 0.35 & Small Effect \\
\hline Visual Recognition (BVMT-R) & -0.404 & 0.947 & 0.27 & Small Effect \\
\hline $\begin{array}{l}\text { Language/Executive Functioning } \\
\text { (COWAT) }\end{array}$ & -0.798 & 0.548 & -0.13 & No Effect \\
\hline Language (Boston Naming) & -0.621 & 0.723 & 0.05 & No Effect \\
\hline Visual-Spatial (Visual Puzzles) & -0.433 & 0.917 & 0.24 & Small Effect \\
\hline Depression (PHQ-9) & -0.939 & 0.412 & -0.26 & Small Effect \\
\hline Perception of Memory (CFQ) & -0.758 & 0.587 & -0.09 & No Effect \\
\hline
\end{tabular}

In order to estimate the clinical magnitude of the differences between pre- and post-intervention measures, effect sizes (Cohen's d) for each independent variable were calculated (see Table 3). Large effect sizes $(>0.80)$ were found for the following cognitive domains: immediate verbal recall and verbal recognition. Moderate effect sizes $(0.50-0.80)$ were found for the following cognitive domains: divided attention and delayed verbal recall. Small effect sizes $(0.20$ 0.49 ) were found for the following cognitive domains: working memory, processing speed 
and executive functioning, immediate and delayed visual recall, visual recognition, and visual-spatial skills. Finally, no meaningful effect sizes $(<0.20)$ were found for the following cognitive domains: simple attention and both language measures. In addition, there was a small effect size on the measure of depression, but none for memory self-efficacy.

\section{Discussion}

Results indicated modest improvements on the majority of measures of cognitive functioning. Several findings were consistent with previous research. For example, similar to previous studies, measures of processing speed and executive functioning showed small improvements (Ball et al., 2002). In addition, improvements on measures of immediate verbal recall, verbal recognition, and delayed verbal recall are consistent with previous research (Ball et al., 2002; Gross et al., 2012). The positive findings regarding verbal memory may be due to the relatively high "dose" of verbal memory exercises in the program (approximately $25 \%$ of class content). Similarly, measures of visual recall, visual recognition, and delayed visual recall all showed a small improvement, a finding consistent with prior literature on the impact of cognitive training on visual and general memory functioning (Ball et al., 2002; Gross et al., 2012).

Exploratory analyses revealed small to moderate improvements in attention and visuospatial skills. These results could be related to the content of the cognitive training classes. For example, the attention exercises in the program involved tasks similar to what is required for the Brief Test of Attention (e.g., presenting target and distractor stimuli and asking participants to report the number of target stimuli detected). In addition, classes included a variety of visuospatial tasks that require mental rotation or reversal of visual stimuli, skills assessed by the Visual Puzzles test.

Language was the only cognitive domain that did not show improvement. One explanation for this finding is that "language" is a very broad construct that consists of a variety of abilities.
Therefore, the instruments used to measure language abilities may not have accurately assessed the specific language skills targeted by the classes. Furthermore, given that the program includes a number of different language exercises, relatively little practice is devoted to specific skills measured in this study (i.e., confrontation naming and verbal fluency).

Results were mixed with regard to measures of non-cognitive domains. Results indicated that cognitive training might have a beneficial effect on mood, a finding consistent with previous research (Brum, Forlenza, \& Yassuda, 2009). This relationship may be due to a general increase in activity, increased socialization, or improved perceptions of cognitive functioning. Although previous studies have found positive changes in memory self-efficacy following participation in cognitive training (Rapp, Brenes, \& Marsh, 2002), the current study did not. It is possible that using a measure of self-efficacy related to broader cognitive functioning, as opposed to memory only, would produce different results.

\section{Limitations and Future Directions}

Some limitations of this study concerned the participant sample. First, the sample used in this study was small and considerably homogenous given that all participants were well-educated Caucasian nuns. Second, the sample was quite heterogeneous with regard to the presence or lack of preexisting medical conditions and mental health status, although medication status for these conditions did not change throughout the study.

Other limitations concerned the assessment process. For example, testing occurred on two different days to prevent fatigue and these two testing sessions did not always occur at the same time of day. In addition, pre- and posttesting was not always conducted at the same time of day for each participant. Given that cognitive functioning in older adults tends to deteriorate as the day continues (Blatter \& Cajochen, 2007), these variations in testing procedures could have resulted in unwanted 
variability in test scores unrelated to the effects of the program.

Most importantly, because this was a pilot study designed to test the potential effects of this cognitive training program, a control group was not included. A control group would be essential to differentiate changes that occurred due to the cognitive training program from those that occur naturally as one ages. Future studies will need to incorporate no-intervention control groups as well as active control groups (e.g., book clubs) to determine if the cognitive training program is responsible for changes in cognitive functioning observed in this study.

\section{Conclusion}

The findings of the current study provide preliminary support for the use of a cognitive training program for cognitively-intact older adults. Small to large improvements were observed on most measures of cognitive functioning and small improvements in depressive symptoms were also found. These results are encouraging, particularly considering that the participants already had high levels of cognitive functioning before the program began, presumably leaving less room for improvement. The cognitive training program utilized in this study has many strengths as it targets six cognitive domains (i.e., was comprehensive), could be completed in one-hour sessions (i.e., were not overly cumbersome compared to similar cognitive training programs), were wellreceived by participants, and the facilitators reported liking the program. However, additional research with larger samples and appropriate control groups is needed before making more definitive conclusions about the efficacy of this cognitive training program.

Conflict of interest statement: The third author serves as a research consultant for the nonprofit organization that created the cognitive training program. The researcher is not on the organization's board nor is he financially compensated for his consultation services.

\section{References}

[1]. Bahar-Fuchs, A., Clare, L., \& Woods, B. (2013). Cognitive training and cognitive rehabilitations for mild to moderate Alzheimer's disease and vascular dementia (review). The Cochrane Library, 2013(6), 1-103. doi:10.1002/14651858.CD003260.pub2

[2]. Ball, K., Berch, D. B., Helmers, K. F., Jobe, J. B., Leveck, M. D., Marsiske, M., ... Willis, S. L. (2002). Effects of cognitive training interventions with older adults: A randomized controlled trial. The Journal of the American Medical Association, 288(18), 2271-2281. doi:10.1001/jama.288.18.2271

[3]. Belleville, S. (2008). Cognitive training for persons with mild cognitive impairment. International Psychogeriatrics, 20(01). doi:10.1017/s104161020700631x

[4]. Benedict, R. H. B., Schretlen, D., Groninger, L., Dobraski, M., \& Shpritz, B. (1996). Revision of the brief visuospatial memory test: Studies of normal performance, reliability, and validity. Psychological Assessment, 8(2), 145153. doi:10.1037//1040-3590.8.2.145

[5]. Benton, A. L. \& Hamsher, K. (1989). Multilingual Aphasia Examination. Iowa City, lowa: AJA Associates.

[6]. Blatter, K. \& Cajochen, C. (2007). Circadian rhythms in cognitive performance: Methodological constraints, protocols, theoretical underpinnings. Physiology \& Behavior, 90(2-3), 196-208. doi:10.1016/j.physbeh.2006.09.009

[7]. Brandt, J. \& Benedict, R. H. B. (2001). Hopkins Verbal Learning Test. Lutz, FL: Psychological Assessment Resources.

[8]. Broadbent, D. E., Cooper, P. F., FitzGerald, P., \& Parkes, K. R. (1982). The cognitive failures questionnaire (CFQ) and its correlates. British Journal of Clinical Psychology, 21(1), 1-16. doi:10.1111/j.2044-8260.1982.tb01421.x

[9]. Brum, P. S., Forlenza, O. V., \& Yassuda, M. S. (2009). Cognitive training in older adults with Mild Cognitive Impairment: Impact on cognitive and functional performance. Dementia \& Neuropsychologia, 3(2), 124-131. doi:10.1590/s1980-57642009dn30200010

[10]. Deary, I. J., Corley, J., Gow, A. J., Harris, S. E., Houlihan, L. M., Marioni, R. E., ... Starr, J. M. (2009). Age-associated cognitive decline. British Medical Bulletin, 92(1), 135-152. doi:10.1093/bmb/ldp033

[11]. Gross, A. L., $\quad$ Parisi, J. M., $\quad$ Spira, A. P., Kueider, A. M., Ko, J. Y., Saczynski, J. S., ... Rebok, G.W. (2012). Memory training interventions for older adults: A meta-analysis. 
Aging \& Mental Health, 16(6), 722-734. doi:10.1080/13607863.2012.667783

[12]. Harada, C. N., Natelson Love, M. C., \& Triebel, K. (2013). Normal cognitive aging. Clinics in Geriatric Medicine, 29(4), 737-752. doi:10.1016/j.cger.2013.07.002

[13]. Hertzog, C., Kramer, A. F., Wilson, R. S., \& Lindenberger, U. (2008). Enrichment effects on adult cognitive development: Can the functional capacity of older adults be preserved and enhanced? Psychological Science in the Public Interest, 9(1), 1-65. doi:10.1111/j.15396053.2009.01034.x

[14]. Kaplan, E., Goodglass, H., \& Weintraub, S. (1983) The Boston naming test. (2nd ed.). Philadelphia: Lea \& Febiger.

[15]. Kroenke, K., Spitzer, R.L., \& Williams, J.B. (2001). The PHQ-9: Validity of a brief depression severity measure. Journal of General Internal Medicine, 16 (9), 606-613. doi: 10.1046/j.1525-1497.2001.016009606.x

[16]. Minett, T.S.C, Da Silva, R.V., Ortiz, K.Z., \& Bertolucci, P.H.F. (2007). Subjective memory complaints in an elderly sample: A crosssectional study. International Journal of Geriatric Psychiatry, 23, 49-54. doi:10.1002/gps.1836

[17]. Owen, A. M., Hampshire, A., Grahn, J. A., Stenton, R., Dajani, S., Burns, A. S., ... Ballard, C. G. (2010). Putting brain training to the test. Nature,465(7299), 775-778. doi:10.1038/ nat ure09042

[18]. Papp, K. V., Walsh, S. J., \& Snyder, P. J. (2009). Immediate and delayed effects of cognitive interventions in healthy elderly: $A$ review of current literature and future directions. Alzheimers \& Dementia, 5(1), 50-60. doi:10.1016/j.jalz.2008.10.008

[19]. Rapp, S., Brenes, G., \& Marsh, A. P. (2002). Memory enhancement training for older adults with mild cognitive impairment: A preliminary study. Aging \& Mental Health, 6(1), 5-11. doi: 10.1080/13607860120101077

[20]. Reitan, R. M., \& Davidson, L. (1974). Clinical neuropsychology: Current status and applications. Washington DC: VH Winston.

[21]. Salthouse, T.A. (2012). Consequences of agerelated cognitive declines. Annual Review of Psychology, 63, 201-226. doi:10.1146/annurev-psych-120710-100328

[22]. Schretlen, D. (1997). Brief test of attention. Lutz, FL: Psychological Assessment Resources.

[23]. Simons, D. J., Boot, W. R., Charness, N., Gathercole, S. E., Chabris, C. F., Hambrick, D.
Z., \& Stine-Morrow, E. A. L. (2016). Do "braintraining" programs work? Association of Psychological Science in the Public Interest, 17(3), 103-186. doi:10.1177/15291006 1666 1983

[24]. Teng, E. L \& Chui, H. C. (1987). The Modified Mini-Mental State (3MS) examination. Journal of Clinical Psychiatry, 48(8), 314-318.

[25]. Wechsler, D. (2008). Wechsler adult intelligence scale: Fourth edition WAIS-IV. New York: The Psychological Corporation. 